\title{
Brimonidine Tartrate Nanoemulsion OCU-300
}

National Cancer Institute

\section{Source}

National Cancer Institute. Brimonidine Tartrate Nanoemulsion OCU-300. NCI Thesaurus.

Code C158723.

An ophthalmic nanoemulsion consisting of the tartrate salt form of brimonidine, an imidazole derivative and selective alpha-2 adrenergic receptor agonist, with potential anti-inflammatory and vasoconstrictive activities. Upon ophthalmic instillation, brimonidine tartrate nanoemulsion OCU-300 reduces intraocular pressure by promoting the outflow and decreasing the production of aqueous humor and may reduce ocular erythema through direct vasoconstriction. Additionally, brimonidine may disrupt leukocyte extravasation into the ocular tissue, inhibit nociception and reduce inflammation associated with ocular graft-versus-host disease (oGvHD). The nanoemulsion formulation may enhance distribution of brimonidine to target tissues, thereby allowing more of the active drug to reach underlying ocular tissue. 